\title{
Cartografia e paisagem: o mapa como objeto de estudo
}

\author{
[Cartography and landscape: the map as an object of study
}

\author{
Mônica Balestrin Nunes ${ }^{\mathrm{I}}$
}

\begin{abstract}
Artigo baseado na tese de doutorado defendida em 20I4 no Departamento de Geografia da FFLCH/USP (Paisagens clandestinas: a estrutura fundiária como componente da paisagem da zona leste paulistana) sob orientação da professora doutora Amália Inés Geraiges de Lemos. A participação no Grupo USP-Cofecub contribuiu para a consolidação dos estudos sobre a importância da cartografia e a sua integração na pesquisa.
\end{abstract}

RESUMO $\cdot O$ objetivo deste artigo é apresentar uma abordagem da cartografia em sua forma objetiva, relacionada à produção e pesquisa de mapas, e também na forma simbólica, como ferramenta de compreensão do espaço, das relações sociais e da paisagem. Está estruturado a partir de breve consideração sobre o papel dos mapas e as relações de poder para em seguida, tratar dos mapas urbanos e como eles podem ser ferramentas na produção das cidades, com a devida distinção entre os mapas que produzem espaço e mapas que são produzidos pelo espaço. O estudo de caso é a cidade de São Paulo, entre I930 e I980. Estas considerações dão suporte à abordagem da leitura das paisagens por meio dos mapas e à aproximação da cartografia com a Geografia Humanista. PALAVRAS-CHAVE . Cartografia; paisagem; espaço; estudos urbanos;
São Paulo. · ABSTRACT - The purpose of this article is to present a cartographic approach in its objective manner related to the production and research maps, and also in symbolic form, such as understanding tool of the space, social relations and landscape. It is structured from a brief consideration regarding the role of maps and the power relationships to then deal with the urban maps and how can they be tools in the production of the cities with due distinction between the maps that produce space and maps that are produced by the space. The case study is São Paulo City, between I930 and I980. These considerations give support to the reading approach of landscapes through the maps and the approximation of the cartography with the Humanistic Geography. - KEYWORDS - Cartography; landscape; space; urban studies; São Paulo.

Recebido em 6 de outubro de 2016

Aprovado em 29 de novembro de 2016

NUNES, Mônica Balestrin. Cartografia e paisagem: o mapa como objeto de estudo. Revista do Instituto de Estudos Brasileiros, Brasil, n. 65, p. 96-II9, dez. 2016.

DOI: http://dx.doi.org/Io.II606/issn.23I6-90IX.voi65p96-II9

I Ministério das Cidades (Brasília, DF, Brasil). 
Este artigo busca trazer reflexões sobre as possíveis formas de leitura da paisagem por meio dos mapas e também uma reflexão sobre o objeto cartográfico e suas diversas funções, objetivas ou não, na prática dos profissionais dos estudos urbanos.

A utilização de mapas faz parte do cotidiano dos profissionais que lidam com o urbano: geógrafos, arquitetos, engenheiros, geólogos. Entretanto, pouco se reflete sobre a função e o significado da cartografia nessas práticas profissionais. A representação gráfica, muitas vezes, assume um caráter naturalizado, como se fosse a representação fiel da realidade. E esse fato leva a distorções de compreensão do espaço que, por consequência, levam a tomadas de decisões equivocadas pela ausência de uma "cultura cartográfica" que suscite discussões sobre a representação do mundo, seus alcances e limitações.

A necessidade da discussão sobre a cartografia em trabalhos acadêmicos e na prática profissional deve-se principalmente ao fato de que o objeto dos estudos urbanos deve ser analisado por meio da representação gráfica - plantas de loteamentos, plantas antigas, a própria cartografia digital -, sem a qual não seriam possíveis as análises. Além disso, norma e cartografia se entrelaçam na produção do espaço e da paisagem que se pretende analisar. Normas urbanísticas são quase sempre passíveis de representação no espaço, e, no sentido inverso, cartografia é também uma espécie de norma.

Do mesmo modo que as normas, as relações sociais também podem ser espacializadas: o espaço passou a ser, na pós-modernidade, fundamental para a compreensão da sociedade. Num interessante exercício de aproximação da cartografia e do direito, Boaventura Sousa Santos afirma:

O espaço parece, pois, transformar-se no modo privilegiado de pensar e agir o fim do século. Assim sendo, é de pensar que as representações sociais do espaço adquiram cada vez mais importância e realidade analíticas. [...]

Todos os conceitos com que representamos a realidade e à volta dos quais constituímos as diferentes ciências sociais e suas especializações, a sociedade e o Estado, o indivíduo e a comunidade, a cidade e o campo, as classes sociais e as trajectórias pessoais, a produção e a cultura, o direito e a violência, o regime político e os movimentos sociais, 
a identidade nacional e o sistema mundial, todos estes conceitos têm uma contextura espacial, física e simbólica, que nos tem escapado².

Essa dimensão e perspectiva de análise da cartografia, entretanto, não é tão evidente na produção geográfica. Fonseca afirma:

Haveria um consenso de que a Cartografia é a linguagem privilegiada para a expressão da Geografia? O que poderia ser uma óbvia resposta afirmativa não o é. Sequer há um consenso quanto ao fato da Cartografia ser considerada uma linguagem ou não. Antes, notamos, que na Geografia brasileira há um uso muito limitado da cartografia e que se trata de um uso despido de discussões epistemológicas atuais³.

Nesse sentido, a abordagem da cartografia, tanto na forma objetiva, da produção e pesquisa de mapas, quanto na forma simbólica, como ferramenta de compreensão do espaço, das relações sociais e, por fim, da paisagem, é o objetivo deste artigo. Discuti-la epistemologicamente é condição para a compreensão dos processos de formação da paisagem urbana. A produção cartográfica, seja a oficial, cadastral, ou ainda a produção privada, representada pelas plantas de loteamentos, revela muito das correlações de força sociais.

Este artigo se estrutura, segundo os seguintes elementos: primeiramente, uma breve consideração sobre o papel dos mapas e as relações de poder: os mapas nunca são isentos, e esta posição é defendida por Harley4. Em seguida, aproximando a escala, são tratados os mapas urbanos e como eles podem ser ferramentas na produção das cidades, conforme se verifica em Cosgrove5; é feita também a necessária distinção entre mapas que produzem espaço e mapas que são produzidos pelo espaço, apoiando-se ainda em Cosgrove. Neste ponto exemplificamos e categorizamos os tipos de mapas segundo sua origem de produção e suas funções.

Uma vez colocados estes pressupostos, são levantados os pontos de convergência da cartografia com a geografia cultural humanista e a paisagem: como um mapa representa a paisagem? Ou, em outro sentido, como "ler" uma paisagem a partir de um mapa?

2 SANTOS, Boaventura Sousa. Uma cartografia simbólica das representações sociais: prolegómenos a uma concepção pós-moderna do direito. Revista crítica de ciências sociais, n. 24, p. I39-I72, março de I988, p. I40-I4I. Disponível em: 〈http://www.boaventuradesousasantos.pt/pages/pt/artigos-em-revistas-cientificas.php〉. Acesso em: II jun. 20I4

3 FONSECA, Fernanda Padovesi. A inflexibilidade do espaço cartográfico, uma questão para a geografia: análise das discussões sobre o papel da cartografia. Tese (Doutorado em Geografia Humana). Departamento de Geografia da Faculdade de Filosofia, Letras e Ciências Humanas, Universidade de São Paulo, São Paulo, 2004, p. I2.

4 HARLEY, B. Mapas, saber e poder. Tradução Mônica Balestrin Nunes. Confins - Revista Franco-Brasileira de Geografia, n. 5, 2009. Disponível em: 〈http://confins.revues.org/5724〉. Acesso em: nov. 2016.

5 COSGROVE, Denis Edmund. Social formation and symbolic landscape. Wisconsin: The University of Wisconsin Press, I998, $293 \mathrm{p}$. 


\section{MAPAS COMO INSTRUMENTO DE PODER}

A abordagem dos mapas como instrumento de poder é necessária para a compreensão dos processos de constituição da estrutura fundiária da cidade de São Paulo. A discussão que se propõe por ora, apoiando-se no artigo de Brian Harley ${ }^{6}$, é refletir sobre como a cartografia pode ser um instrumento de exercício do poder político e social. A produção cartográfica está ligada aos contextos históricos e ideológicos das sociedades; ela pode revelar ou omitir informações segundo os objetivos de quem detém a autoridade sobre a informação.

A proposta de Harley é que a leitura dos mapas seja feita a partir de três perspectivas: o contexto político dos mapas, sua utilização no exercício do poder e a simbologia dos elementos.

Os mapas serão considerados como parte integrante da família mais abrangente das imagens carregadas de um juízo de valor, deixando de ser percebidos essencialmente como levantamentos inertes de paisagens morfológicas ou como reflexos passivos do mundo dos objetos. Eles são considerados imagens que contribuem para o diálogo num mundo socialmente construído7.

Entender o contexto político da produção cartográfica auxilia a compreensão das representações e do que "se esconde" por trás dos mapas: características sociais, culturais, econômicas e religiosas. Historicamente, os mapas foram repositório de informações privilegiadas, e sua produção estava ligada às elites: elites dinásticas no Egito antigo, elites religiosas na Europa Medieval ou elite mercantil na Europa Renascentista.

Um aspecto a ser considerado no contexto dos mapas como ferramentas do poder reside no fato de que, ao representar o território em papel, eliminavam-se as "interferências" da realidade, ou seja, a presença de populações inteiras podia ser simplesmente ignorada na divisão política de terras entre colonizadores, como, por exemplo, foi o caso da divisão das colônias da África.

Quanto ao conteúdo dos mapas e suas funções no exercício do poder, Harley afirma que os mapas podem conter imprecisões intencionais ou inconscientes, omitir informações (o silêncio dos mapas) e ainda definir hierarquias segundo um objetivo prévio.

As distorções intencionais dos mapas geralmente servem à propaganda política e ideológica, impostas pelo governo ou por interesses particulares. O "silêncio" dos mapas consiste na omissão de determinadas informações com a finalidade de ressaltar outras características mais importantes do território. Por fim, a hierarquia pode ser utilizada como forma de atrair a atenção para pontos específicos.

Os elementos iconográficos presentes nos mapas também merecem atenção do autor, na medida em que as imagens, ornamentos e adereços presentes nos mapas se tornam parte da mensagem a ser transmitida.

6 HARLEY, Brian, op. cit.

7 Ibidem, p. 2. 
Não se pretende o detalhamento da proposta de Harley na leitura dos mapas, mas uma referência aos conceitos por ele desenvolvidos, de modo que a leitura do estudo de caso permita relacioná-los com a observação empírica.

Pensar a cartografia brasileira nos termos colocados por Harley é uma tarefa que pode ser cumprida considerando alguns pressupostos: inicialmente, é que nossa cartografia está ligada na sua origem à cartografia europeia do século XVI - os mapas dos descobrimentos, as primeiras expedições, os primeiros viajantes imprimiram suas visões da nova terra segundo os interesses da Coroa e segundo as finalidades a que se propunham.

A cartografia colonial brasileira, segundo Archela ${ }^{8}$, teve de início o objetivo de reconhecimento da costa; em seguida, procurou-se mapear os limites do interior e as fronteiras, mas foi a partir do século XVIII, com a descoberta do ouro em Minas Gerais, que a cartografia ganhou impulso.

Mas a primeira sistematização oficial deu-se com a Comissão da Carta Geral do Império - CCGI, segundo Vergara e Capilé:

A CCGI tem seu início em I864 [sob] as ordens da Inspeção Geral das Obras Públicas do Ministério da Agricultura, do Comércio e das Obras Públicas (MACOP), entidade que efetuava também os serviços da triangulação do município neutro, as plantas cadastrais da cidade do Rio de Janeiro, e obras de edificação, estradas e condução e distribuição de águas. Os resultados concretos só foram percebidos no final de I866, tendo como principal argumento a lentidão[causada pela] dificuldade de encontrar profissionais hábeis em desenho e nas técnicas de astronomia e geodésia, o que marcou seus primeiros anos?.

Os autores apontam ainda que a criação da comissão, no dizer de um de seus integrantes, teve como objetivo conhecer o Brasil e dar conhecimento ao mundo dos avanços do país. Segundo os autores:

Nesse momento da criação da Carta Geral do Império vemos que esta tem a se destacar como um símbolo de prosperidade e progresso da nação, o que talvez possa ser explicado com os dois momentos de sua publicação: a Exposição Nacional de 1875 e a Exposição Universal da Filadélfia de I876. Nesse instante o uso de mapas para este fim já era [comum] no mundo afora, e observa-se que elementos estéticos tornam-se cada vez mais presentes, já que esses mapas já não são mais enrolados após seu uso, [mas são expostos] definitivamente ${ }^{\mathrm{Io}}$.

8 ARCHELA, R. S. História da cartografia no Brasil: instituições, formação profissional e técnicas cartográficas. Revista brasileira de cartografia, n. 59, dez. 2007, p. II-37.

9 VERGARA, M. R.; CAPILÉ, B. A Comissão da Carta Geral do Império (I862-I878) e sua participação no contexto da cartografia brasileira no Império. In: SIMPÓSIO BRASILEIRO DE CARTOGRAFIA HISTÓRICA, I. Anais..., 20II, Paraty, Io a I3 de maio de 20II, p. 4 (destaques nossos). Disponível em: <https://www.ufmg. $\mathrm{br} /$ rededemuseus/crch/simposio/VERGARA_MOEMA_R_E_CAPILE_BRUNO.pdf $\rangle$. Acesso em: 25 ago. 20I4.

Io Ibidem, p. 5 . 
Em que pese a necessidade de conhecimento do território, vê-se nesse caso um exemplo da utilização do mapa como exercício do poder: era importante para o Brasil divulgar, na exposição do ano do centenário dos Estados Unidos, um trabalho de relevância técnica.

Mas, além dos objetivos políticos, a elaboração da carta enfrentou dificuldades técnicas e operacionais, como a ausência de profissionais qualificados, equipamentos e, sobretudo, pela ausência de retorno de informações das províncias.

É de destacar a reprodução do relatório do último presidente da CCGI:

[Henrique de Beaupaire] Rohan prossegue e compara as atividades cartográficas ocorridas para a carta da França no século XVIII com as atividades ocorridas no Brasil. Ao equiparar as superfícies quadradas de ambos os países supôs somente ser possível a realização da Carta Geral do Império em 800 anos, ou em 50 anos com um pessoal dezesseis vezes maior (Rohan, I877) ${ }^{\text {II }}$.

No que se refere ao mapeamento não institucional, os problemas eram ainda maiores: por ocasião da promulgação da Lei de Terras, em I850, as legitimações de posse anteriores à lei deveriam ser submetidas à Coroa; e as propriedades, devidamente medidas. Nesse caso, cabia aos concessionários a responsabilidade do mapeamento, mas, diante da necessidade de definir com precisão os limites das posses, que eram muito maiores do que o concedido, simplesmente não havia interesse nesse cadastro.

Como se vê, a produção cartográfica brasileira, herdeira da cartografia portuguesa, não é exceção em nenhum dos aspectos abordados por Harley. Desde os primeiros mapas do descobrimento, passando pelos mapas do território e dos cadastros, podemos sempre aplicar a análise do mapa como instrumento de poder, seja do político-institucional, seja do econômico privado. No caso brasileiro, há que se destacar a sistematização tardia da produção cartográfica oficial.

As distâncias tecnológicas entre a produção cartográfica nacional e a europeia podem ser analisadas não só pela ausência de tradição científica, mas também pelo desinteresse das autoridades e pela baixa capacitação técnica dos profissionais. $\mathrm{O}$ eventual interesse do governo em "conhecer" o território esbarra na força do poder econômico dos proprietários de terras. A estrutura social brasileira é o fator de maior distinção na forma como os cadastros e registros fundiários se estabeleceram no Brasil: enquanto para a sociedade burguesa europeia o conhecimento do território era necessário ao controle do Estado, sobretudo pela tributação, na sociedade brasileira de herança colonial, mesmo após a independência, o controle estava nas mãos dos grandes proprietários de terra, para os quais o desconhecimento e o descontrole eram a maior proteção e garantia de seus direitos individuais.

Essa característica irá permear toda a constituição do território brasileiro e se estenderá até os dias atuais, como se verifica nos conflitos por terra, na ausência de reforma agrária e também na distribuição da terra urbana.

Nesse sentido, tem-se uma verdadeira negação do mapa, o que poderia ser

II Ibidem, p. 2. 
acrescentado à teoria de Harley: a ausência do mapa também é uma forma de exercício do poder.

\section{OS MAPAS E AS CIDADES - A CARTOGRAFIA E AS REPRESENTAÇÕES DO URBANO}

Não é comum a reflexão sobre os mapas e as representações do urbano a partir de uma visão da representação, mas sim do objeto representado. Em geral, o que se busca analisar é a forma produzida a partir do mapa, e não o contrário. O mapa, ou a planta, ou o desenho, raramente é visto como um elemento autônomo, como objeto. Segundo Lussault ${ }^{\mathrm{t2}}$, o mapa não é $o$ espaço, mas é um espaço. Mapas urbanos podem anteceder a cidade ou simplesmente registrá-la a posteriori ${ }^{\mathrm{T}}$, mas de que são feitos eles? Que história podem guardar e nos revelar a partir de leituras e referenciais que se alteram no tempo?

Cosgrove diz que o espaço urbano e o espaço cartográfico são inseparáveis. Sua abordagem no artigo refere-se à forma como os mapas urbanos se situam entre criar e registrar as cidades. Mapas são instrumentos de descoberta e de visualização de cidades, mesmo das que já não existem mais.

Ele afirma que as origens urbanas, o conhecimento das primeiras cidades, como as do Vale do Ur ou da Suméria, por exemplo, puderam ser reconstituídas a partir do mapeamento do traçado de suas ruas. Segundo ele, a elevação (as edificações) é a forma urbana menos durável. A projeção horizontal, porém, permite que o mapeamento vá descobrindo, camada por camada, não só os aspectos físicos de uma cidade, mas também a sua vida cultural, social, política e religiosa ${ }^{\mathrm{I}}$.

Para Cosgrove, um conceito importante é o modo como os mapas podem servir para o registro das cidades, ou então como podem ser utilizados para planejar e desenhar suas ampliações ou mesmo a criação de uma nova localidade:

Conceitualmente, o mapa tem tanto precedido a presença física da cidade quanto servido para regular e coordenar a sua continuidade. São Petersburgo, Washington D. C., Nova Délhi, Brasília, incontáveis fortalezas e cidades coloniais existiram no papel antes de terem qualquer expressão material. Paris, Roma, Viena, Amsterdã, Jerusalém - virtualmente, toda grande cidade - foram construídas ou expandidas por meio de um plano desenhado. E, além da extensão física de reconstrução do espaço urbano, o mapa registrou e determinou incontáveis aspectos da vida urbana e da cidadania ${ }^{15}$.

Mapas que antecedem cidades são aqueles mapas elaborados a partir de um projeto de cidade; por sua vez, os mapas que registram são aqueles elaborados para

I2 LUSSAULT, Michel. L'homme spatial: la construction sociale de l'espace humain. Paris: Éditions du Seuil, 2007. (Coll. La couleur des idées).

I3 COSGROVE, Denis Edmund. Carto-city. In: ABRAMS, Janet; HALL, Peter (Org.). Else/where: mapping - new cartographies of networks and territories. Minneapolis: University of Minnesota Design Institute, 2006.

I4 Ibidem, p. I48.

I5 Ibidem (tradução nossa). 
determinada finalidade: cadastro, tributação, rotas etc. Em ambos os casos, há contextos sociais, políticos e até mesmo econômicos a serem considerados: projetos de cidades, não raro, eram objeto de concursos, como o de Brasília, mas também encomendados a profissionais ligados aos governantes, como Aarão Reis, que projetou Belo Horizonte, assim como levantamentos cadastrais. Parece-nos oportuno, entretanto, fazer a distinção entre mapas de planejamento (que antecedem a cidade) e mapas cadastrais (que registram a cidade), o que nos permitirá compreender melhor a produção cartográfica e suas relações com o contexto socioeconômico. O recorte será a cidade de São Paulo, e o período, de I930 a I980.

No caso das plantas oficiais, há a distinção entre plantas cadastrais e plantas de projeto. Ambas podem explicar processos de produção da cidade: no caso das cadastrais, a representação da "realidade" urbana está sujeita a limitações de ordem tecnológica, econômica ou até mesmo política. Já as plantas de projetos representam ideias muitas vezes modificadas na implantação, quando não ideias e projetos nunca concretizados, o que também tem um significado.

Fonseca e Oliva propõem a discussão sobre os projetos para a cidade de São Paulo, seus impactos e as representações geradas. Citando como exemplos o Plano de Avenidas de Prestes Maia e a representação da Lei de Zoneamento, afirmam:

Após as reflexões e articulações sobre o urbano e as representações visuais, será exemplificado como elas podem se transformar em elementos metodológicos no caso da metrópole de São Paulo. Um critério que pode ser um primeiro passo é a identificação de eventos e processos que tiveram peso na dinâmica da urbanidade, e que também foram intensos geradores de representações visuais. A ligação entre essas duas realidades costuma ser intensa ${ }^{\mathrm{T}}$.

Adotando essa linha metodológica e aliando-a à classificação entre mapas cadastrais e mapas de planejamento, examinaremos alguns casos representativos.

\section{Mapas cadastrais e de diagnóstico}

Os mapas que representam a cidade a posteriori são utilizados em diferentes aplicações, servindo a fins fiscais, como no caso das Plantas Genéricas de Valores, mas também como base para projetos de intervenções urbanas, como nas desapropriações para melhoramentos viários, por exemplo. São cadastrais porque apresentam as informações fundiárias e de configuração urbana em detalhes.

Denominamos aqui, como mapas de diagnóstico, aqueles que reúnem informações tanto para o planejamento urbano, como para outras políticas setoriais.

Os casos a seguir tratados referem-se a momentos específicos da administração da cidade de São Paulo: a Planta Sara, da década de I930, é reconhecida pela qualidade do levantamento e pelo ineditismo da tecnologia utilizada fora da Europa, num momento em que a cidade se encontrava em processo de expansão; já o levantamento

I6 FONSECA, Fernanda Padovesi; OLIVA, Jaime. Reflexões sobre o urbano, a cartografia e a iconografia: o caso da metrópole de São Paulo. Revista Geografia e Pesquisa, Ourinhos, v. 5, n. 2, p. II-38, 20I3, p. 29-30. 
da pesquisa Sagmacs se insere no contexto da urbanização consolidada e com forte espraiamento urbano.

\section{O mapa oficial cadastral: a Planta Sara e a memória urbana}

O levantamento aerofotogramétrico cadastral, que ficou conhecido como Levantamento Sara Brasil, foi contratado em I928 pelo então prefeito de São Paulo, José Pires do Rio. Sua intenção era dotar a cidade de um mapa preciso numa escala adequada ao planejamento (I:I.00o), que iria substituir os antigos mapas gerais da cidade. A gestão de Pires do Rio (I926-I930) foi marcada por várias iniciativas de melhoramentos da cidade, dentre elas, o projeto de retificação do Rio Tietê, encomendado a Saturnino de Brito, e o levantamento Sara Brasil, iniciado em I928.

O levantamento Sara foi um trabalho inédito de aerofotogrametria, demandando grande mobilização de profissionais e equipamentos, até mesmo aviões, que foram trazidos da Itália para o trabalho. Segundo $\mathrm{Lima}^{\mathrm{I7}}$, o levantamento demorou mais que o previsto, por uma série de razões, dentre elas, o fato de a empresa De Agostini, gráfica responsável pela impressão das plantas, não ter capacidade para imprimir mais de 20 folhas por dia, a crise de I929, que impactou a economia mundial, e, por último, a extensão da cidade. Mas o trabalho foi entregue em I933, formando um conjunto de 82 folhas na escala I:5.000 e 5I folhas na escala I:I.000, escala adotada para a área mais central da cidade.

A partir do levantamento Sara Brasil, o planejamento urbano teve à sua disposição uma ferramenta de conhecimento do território do município sem precedentes. Como afirmam Fonseca e Oliva ${ }^{18}$, "o Plano de Avenidas se beneficiou de um trabalho cartográfico magnífico para época, e que demonstra o poder dos mapas como operador na reestruturação urbana”.

De fato, a representação da área do município de São Paulo, em escala grande, I:I.Ooo, com cadastro das edificações, curvas de nível, hidrografia e pontos notáveis, foi um trabalho que só seria refeito em I972-I974, quarenta anos depois, em escala I:2.000. Outro levantamento aerofotogramétrico foi realizado em I954, pela Vasp-Cruzeiro, que, todavia, não se compara em qualidade técnica e metodologia com o Sara Brasil.

Ao nos debruçarmos sobre a teoria apresentada classificando os mapas Sara como mapas oficiais cadastrais e ao aceitá-los como um registro da "realidade" da cidade, podemos tecer algumas considerações quanto ao contexto histórico de sua produção, quanto à estética e qualidade técnica do mapa como objeto e quanto ao seu conteúdo e significado.

Compreender o contexto histórico da produção do levantamento Sara Brasil envolve avaliar que a cidade de São Paulo estava passando por um período de crescimento demográfico causado pela intensificação da imigração estrangeira (só nas três primeiras décadas do século XX a população passou de 240 mil para quase

I7 LIMA, Erly Caldas de. O levantamento pioneiro da Sara Brasil: histórico, tecnologia empregada e avaliação dos produtos. Dissertação (Mestrado em Engenharia). Escola Politécnica, Universidade de São Paulo, 2013.

I8 FONSECA, Fernanda Padovesi; OLIVA, Jaime, op. cit., p. 3I. 
I milhão de habitantes) e pela industrialização financiada pela cultura cafeeira. As elites já se instalavam em locais mais distantes do centro, ocupando as áreas mais altas, como o espigão da Avenida Paulista.

Mas foi um período conturbado no campo político e econômico. Em I924, São Paulo esteve sob o domínio das forças tenentistas por vários dias. Em I929, a quebra da bolsa de Nova York e, em I930, o golpe de Estado dado por Getúlio Vargas, que precedeu a Revolução Constitucionalista em I932, não permitem afirmar que tenha sido um período de tranquilidade para a administração municipal. Ainda assim, Pires do Rio, em seu mandato de I926 a I930, conseguiu entabular essas iniciativas, respaldado pelas decisões da Câmara de Vereadores.

Em termos estéticos e de qualidade técnica, as folhas obedecem aos padrões da época de precisão cartográfica, mas também consistem num material muito bem organizado em termos de informações, legendas etc. $O$ fato de ter sido impresso em litografia, técnica que permite a impressão colorida, faz com que se tenha um mapa visualmente agradável, de fácil leitura imagética. Mesmo nas escalas menores os mapas são extremamente legíveis.

Por fim, um conjunto de mapas que serviu como instrumento de cadastro, de representação da "realidade" de determinado período, hoje continua sendo utilizado como referência histórica. Inúmeros trabalhos, acadêmicos ou não, utilizam os mapas Sara como base: o mapa, nesse caso, muda de função sem mudar na sua essência - ele nos transmite a imagem de uma cidade do passado, de suas relações espaciais e de organização da sociedade daquela época. Nesse sentido, o mapa registra não só uma situação do presente, mas também um retrato do passado. O mapa é o espelho da memória. 


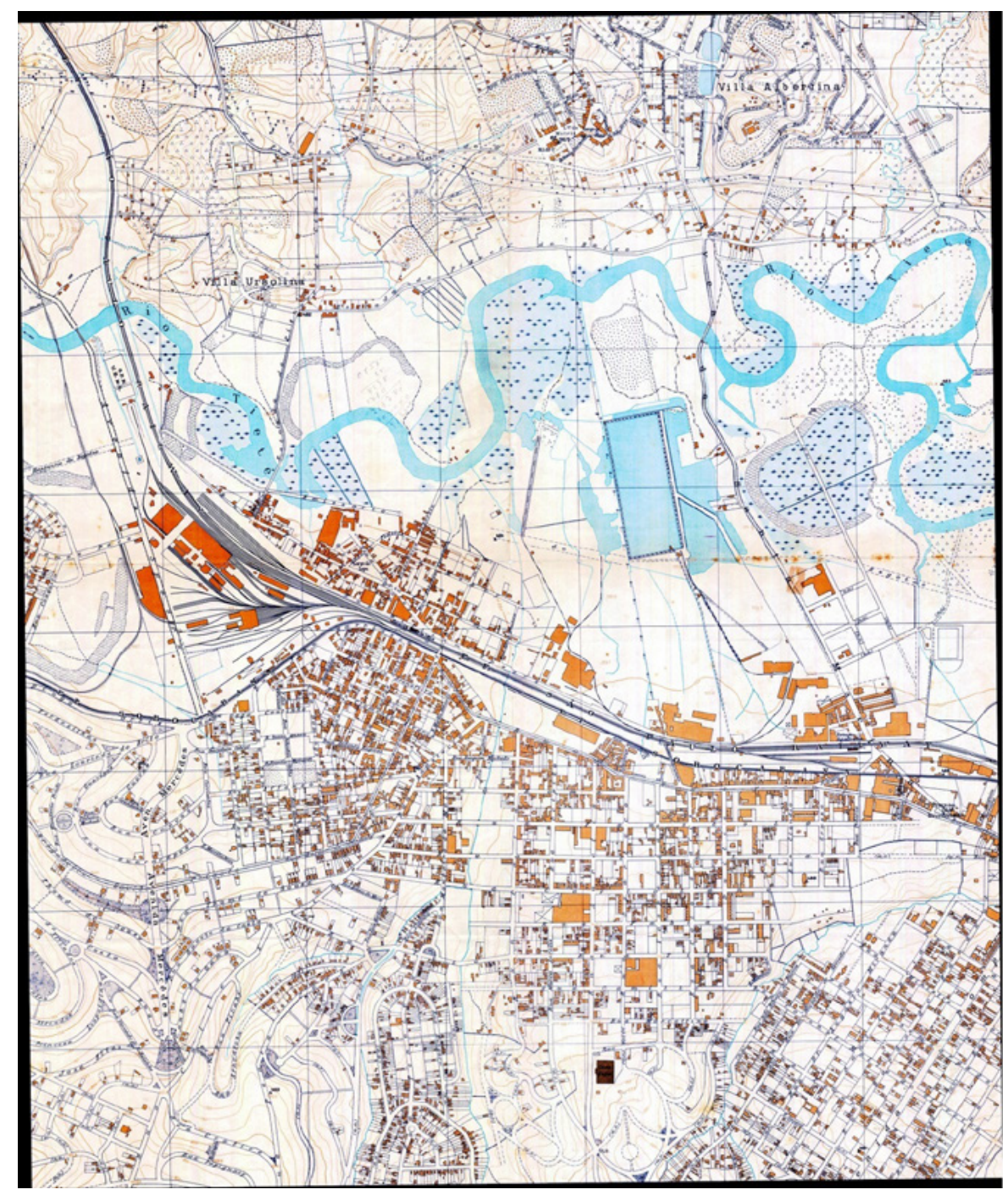

Figura I - Folha 35 do Levantamento Sara. Região da Lapa, zona oeste da cidade de São Paulo. Fonte: Laboratório de Cartografia do Departamento de Geografia da Faculdade de Filosofia Letras e Ciências Humanas (DG/FFLCH/USP)

\section{O mapa diagnóstico social: a pesquisa Sagmacs e o diagrama "margarida"}

Outro tipo de representação da cidade de característica peculiar é a que encontramos no relatório do trabalho que ficou conhecido como "Pesquisa Sagmacs" ${ }^{\text {э. }}$. Coordenada pelo padre Louis Joseph Lebret, no contexto do movimento humanista, essa pesquisa

I9 Sociedade para Análises Gráficas e Mecanográficas Aplicadas aos Complexos Sociais. 
foi encomendada pela prefeitura para o conhecimento da realidade da aglomeração paulistana. Seu título oficial é: "Estrutura urbana da aglomeração paulistana".

Essa pesquisa consistiu num grande levantamento, que envolveu mais de cem profissionais, divididos em grupos temáticos de pesquisa, ressaltando-se seu caráter multidisciplinar. Foi realizada de I956 a I958, e o material produzido é uma representação socioeconômica da aglomeração paulistana, envolvendo não só o município, mas também o que foi chamado de "Great São Paulo".

Em termos dos mapas produzidos, chamam a atenção a simplificação do fundo do mapa e a utilização de hachuras para a representação das diferentes categorias. Mas outro aspecto é peculiar: a utilização do gráfico "margarida" para representar as variáveis pesquisadas.

A metodologia adotada por Lebret e, por conseguinte, pelo Movimento Economia e Humanismo (EH) era a de interpretação da realidade social por meio de levantamentos estatísticos comprovados pela verificação empírica. Segundo Cestaro:

O empirismo era visto por Lebret como uma maneira mais humanizada de se conseguirem os dados referentes à realidade social e econômica da sociedade. Porém, era necessário que os dados obtidos em suas pesquisas de campo se constituíssem em um diagnóstico e um relatório com os apontamentos. Por isso, EH introduzira os diagramas como forma de representação gráfica ${ }^{20}$.

Esses diagramas eram compostos por variáveis que se pretendia representar dispostas de forma radial, onde cada raio (ou pétala) corresponderia a uma variável. O tamanho dos raios é quantitativo da variável. Assim, num esquema como o que se vê na figura 2, quanto mais o traço a partir do centro se aproxima do último círculo, maior é sua quantidade na unidade pesquisada.

20 CESTARO, Lucas. Urbanismo e humanismo: a Sagmacs e o estudo da "Estrutura urbana da aglomeração paulistana”. Dissertação (Mestrado em Teoria e História da Arquitetura e do Urbanismo). Programa de Pós-graduação em Arquitetura e Urbanismo. Escola de Engenharia de São Carlos, Universidade de São Paulo, 2009, p. І30. 


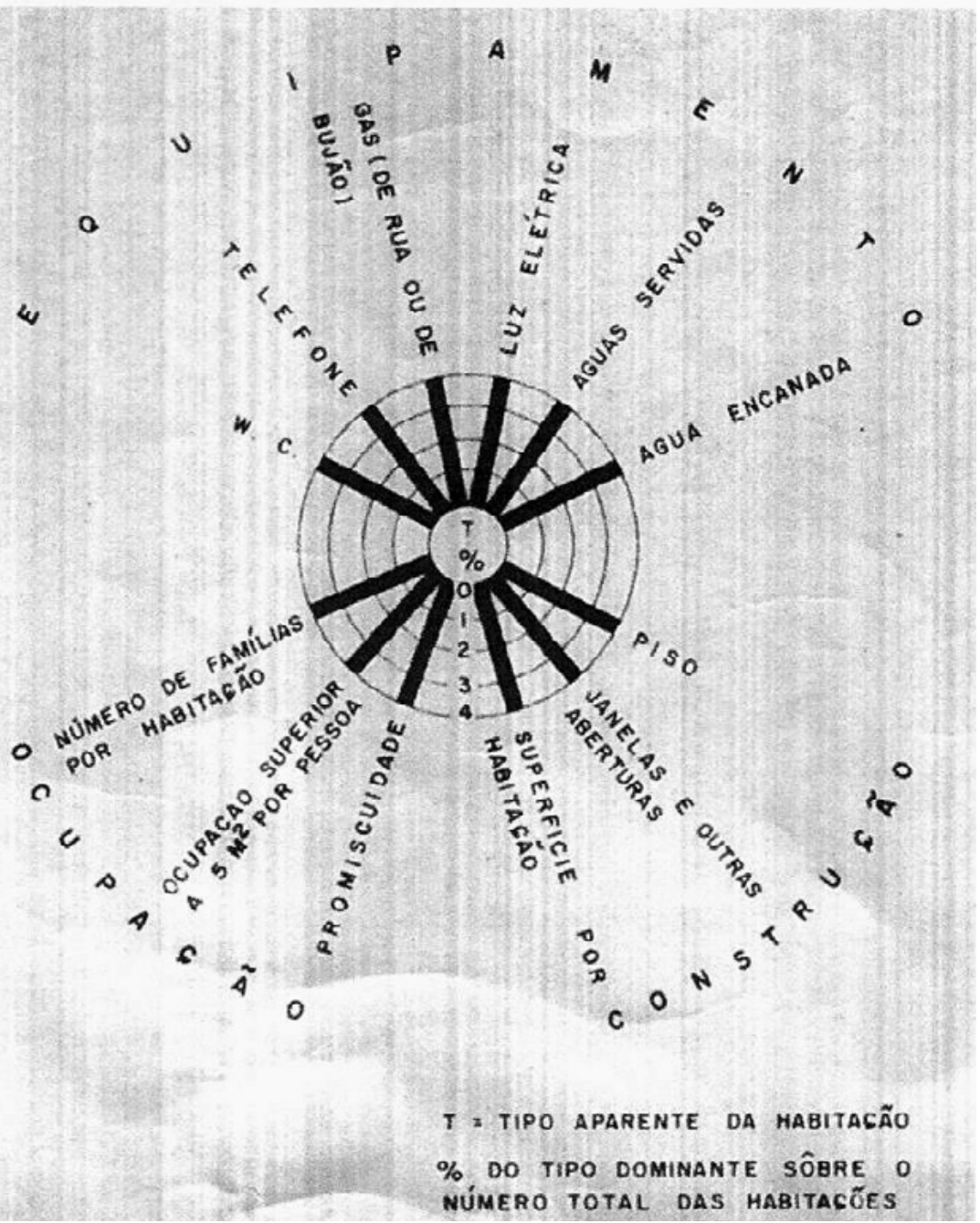

Figura 2 - Legenda do Gráfico da Margarida, com as tipologias habitacionais encontradas. Fonte: CESTARO, L., 2009, p. I50 


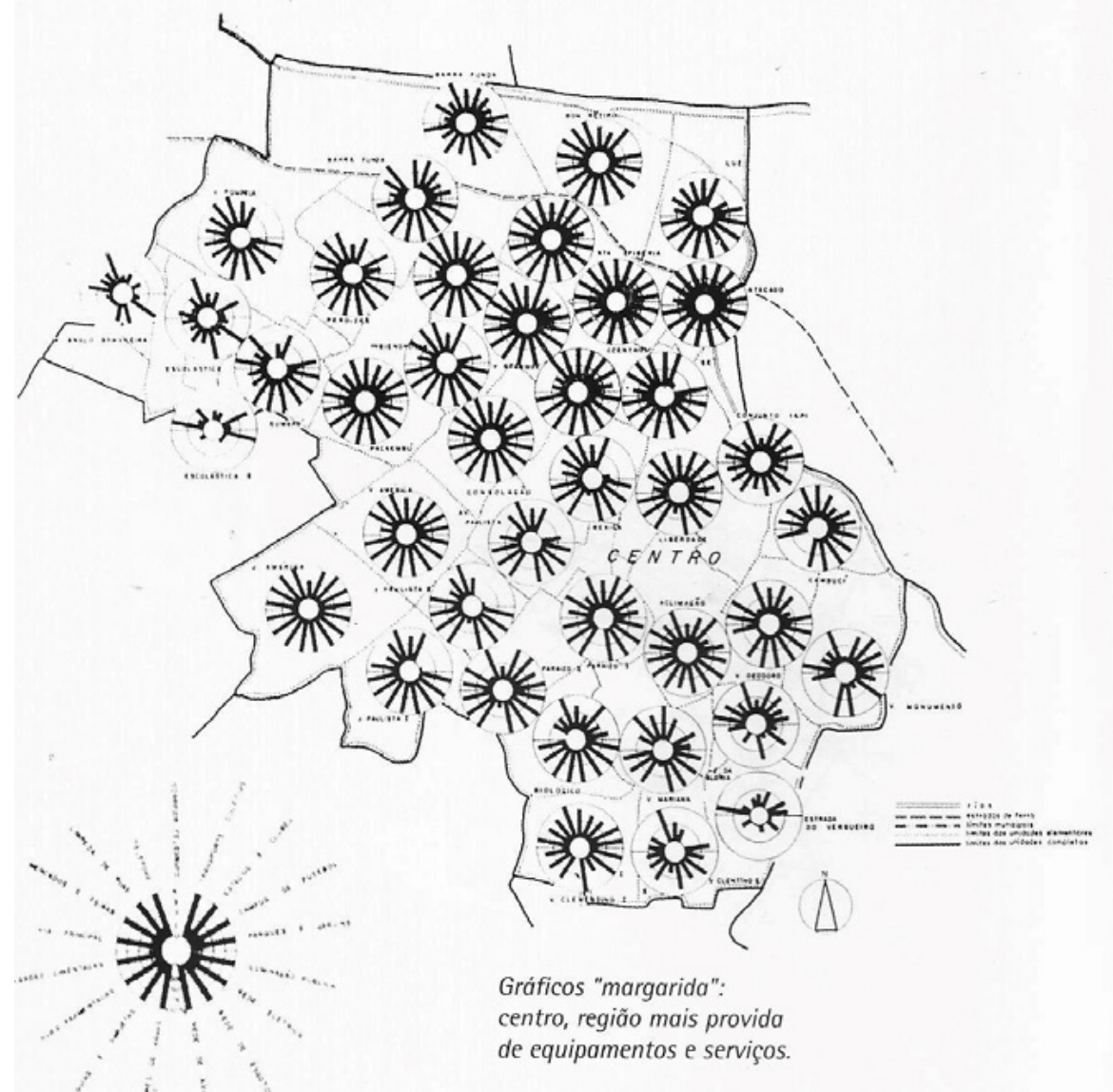

Figura 3 - Exemplo de gráfico margarida na área central. Fonte: ANTONUCCI, D., 2002, p. IO3

Na figura 3, observa-se como fundo de mapa os perímetros dos distritos da área central e os gráficos margarida representando a provisão de serviços, segundo Antonucci ${ }^{21}$; note-se que as "margaridas" possuem todas as pétalas, ou seja, as variáveis medidas encontram-se em nível muito próximo do máximo possível.

Já, na figura 4, a mesma representação, mas para a zona leste. Nota-se que as "pétalas" já não estão presentes em todos os gráficos e seu comprimento é mais curto. A representação da pesquisa Sagmacs é peculiar de um momento do urbanismo paulistano em que se buscava a compreensão dos fenômenos urbanos por meio de diagnósticos extensos, que, no entanto, não tinham continuidade. Essa pesquisa talvez tenha sido pioneira na representação gráfica dos componentes socioeconômicos da cidade, mapeando a oferta de serviços, infraestrutura, habitação, renda etc. Tem-se,

2I ANTONUCCI, D. Sagmacs: o estudo que fez escola. In: SOMEKH, N.; CAMPOS, Candido Malta (Org.). A cidade que não pode parar. Planos urbanísticos de São Paulo no século XX. São Paulo: Mackpesquisa, 2002, p. 95-I08. 
portanto, um gênero de mapa pouco estudado, que em alguma medida registra não os aspectos físicos, mas os aspectos socioeconômicos do urbano.

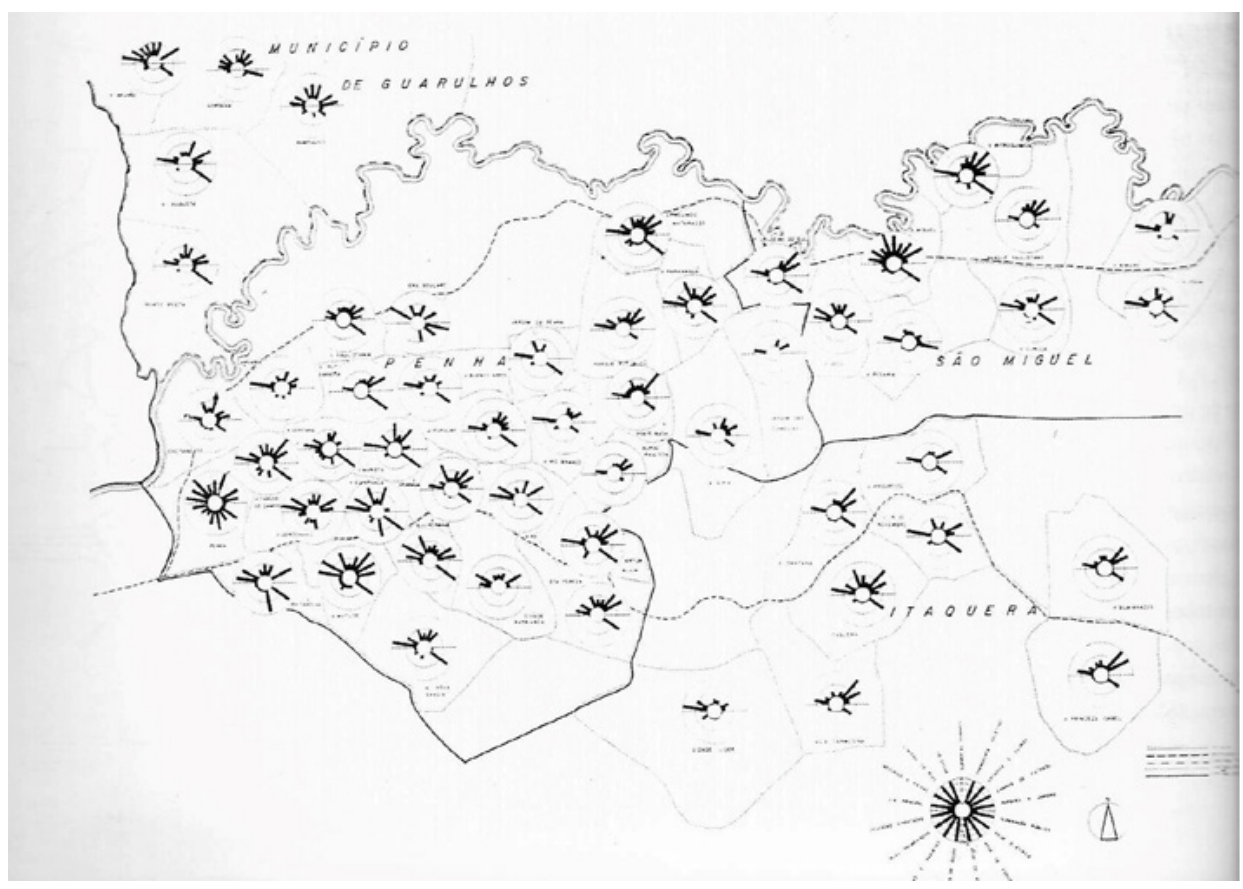

Figura 4-Exemplo de gráfico margarida na zona leste. Fonte: ANTONUCCI, D., 2002, p. IO3

\section{Mapas oficiais de planejamento}

Os mapas de planejamento constituem uma fonte de pesquisa de mão dupla: se, por um lado, permitem a comparação entre a cidade idealizada e a cidade materializada quando os projetos são implantados, por outro, permitem conhecer o que não foi concretizado, e assim estabelecer hipóteses do que e como poderia ter sido. Obviamente há razões para a não concretização dos projetos, que dependem fundamentalmente dos contextos históricos e políticos. Há ainda os casos em que são implantados apenas parcialmente, e a estrutura de conjunto de ações se rompe quando apenas uma parte do projeto é implantada.

Traremos a título de exemplo dois tipos de mapas de planejamento: o projeto de intervenção urbana (exemplificado pela retificação do Rio Tietê) e a representação da norma sobre o território - o mapa do zoneamento. 
O primeiro e mais significativo projeto de Saturnino de Brito é o da retificação do Rio Tietê, já estudado em Nunes ${ }^{22}$. A principal motivação para a obra era a necessidade de saneamento da várzea do rio, que recebia esgotos domésticos, sua baixa declividade e consequente espraiamento das águas, o que causava a formação de alagados propícios à proliferação de doenças.

Segundo Nunes:

Firmiano Pinto constituiu então em I924 a Comissão de Melhoramentos do Rio Tietê e incumbiu o $\mathrm{Eng}^{\circ}$ Sanitarista Francisco Saturnino Rodrigues de Brito de elaborar o plano para saneamento da várzea e retificação do Rio Tietê.

O programa solicitado à Comissão compreendia estudos para três aspectos: I) obras contra inundações; 2) navegação; 3) descarga de esgotos.

Em seu relatório final, Saturnino de Brito apresenta o projeto que previa a retificação do curso do rio, diminuindo sua extensão de $46,3 \mathrm{~km}$ para $26 \mathrm{~km}$, em canal trapezoidal. Isso diminuiria a área inundável e aumentaria a vazão do rio. Propôs também a criação de reservatórios a montante para a retenção das águas e a eliminação dos esgotos através da captação por coletores e um emissário de esgotos.

O plano de Brito foi o mais importante e consistente, pois não só abrangia os aspectos técnicos, como também contemplava a inserção urbanística do projeto, considerando o rio como elemento da paisagem e fazendo uso de seus atributos para o desfrute da população, características presentes em todas as suas obras ${ }^{23}$.

Além disso ele apontava alternativas de viabilidade econômica para custeio das obras, bem como mecanismos e instrumentos de sua implementação, uma vez que a valorização da terra, quando realizadas as obras, era inevitável. Havia ainda a questão das desapropriações e como ficariam as terras de propriedade municipal.

A figura 5 apresenta o projeto de Saturnino de Brito para o Rio Tietê: na parte superior, o traçado original do rio e, embaixo, o projeto com a identificação das áreas inundáveis e áreas verdes. Traz ainda o dimensionamento das seções transversais trapezoidais. Assim como na planta Sara, a qualidade estética é indiscutível. Esse mapa faz parte do volume XIX das Obras completas de Saturnino de Brito ${ }^{24}$. Na

22 NUNES, Mônica Balestrin. A configuração espacial da várzea do Rio Tietê: a região da Água Branca e as áreas públicas municipais. Dissertação (Mestrado em Estruturas Ambientais Urbanas). Faculdade de Arquitetura e Urbanismo, Universidade de São Paulo, São Paulo, 2004

23 Ibidem, p. 87.

24 BRITO, Francisco Saturnino Rodrigues de. Obras completas. V. XIX. Defesa contra inundações. Rio de Janeiro: Imprensa Nacional, I944. 
página seguinte, vê-se uma imagem do que foi realmente executado, na planta de melhoramento viário aprovada em 1927.

Observa-se que a retificação foi muito maior do que a proposta por Brito, inclusive com a eliminação da ilha na altura da ponte grande, hoje Ponte das Bandeiras. Segundo Nunes:

No Boletim do Instituto de Engenharia de março de I933, o então prefeito nomeado Theodoro Ramos relata as modificações ocorridas no projeto de Saturnino de Brito, que já havia falecido. Ele aponta as dificuldades que Saturnino encontrou em I925 para estabelecer a medição de vazões e o regime do rio, por falta de dados anteriores e pela grande seca que a cidade enfrentou em I924 e I925.

Entretanto, de I925 a I929 - ano da grande cheia - foram feitas segundo ele várias sondagens e estudos, bem como as obras da barragem de Parnahyba e do Rio Pinheiros projetadas pela Light \& Power, que levaram à necessidade de modificação do projeto original de Brito, com o aprofundamento do canal e redução de sua largura, e menor área de aterro.

Outra questão colocada pelo prefeito como fator que levou à modificação do projeto diz respeito ao valor da terra e às vantagens auferidas pelos proprietários:

"Relativamente ao projecto elaborado em I925, o traçado do eixo longitudinal do canal comporta algumas modificações; assim, em consequencia da attitude de alguns proprietários de certo trecho de terrenos comprehendido pelo projecto, que exigiram indemnizações exaggeradas pelas suas propriedades, foi adoptada uma variante do projecto organizado, desviando-se desses terrenos, para attingir outros de preços muito mais baixos." Boletim do I. E. (março/I933, p.I90)25.

Observa-se, assim, que há mapas que "desenham" a cidade, mas não "produzem" a cidade efetivamente.

25 NUNES, Mônica Balestrin, op. cit., p. 88. 


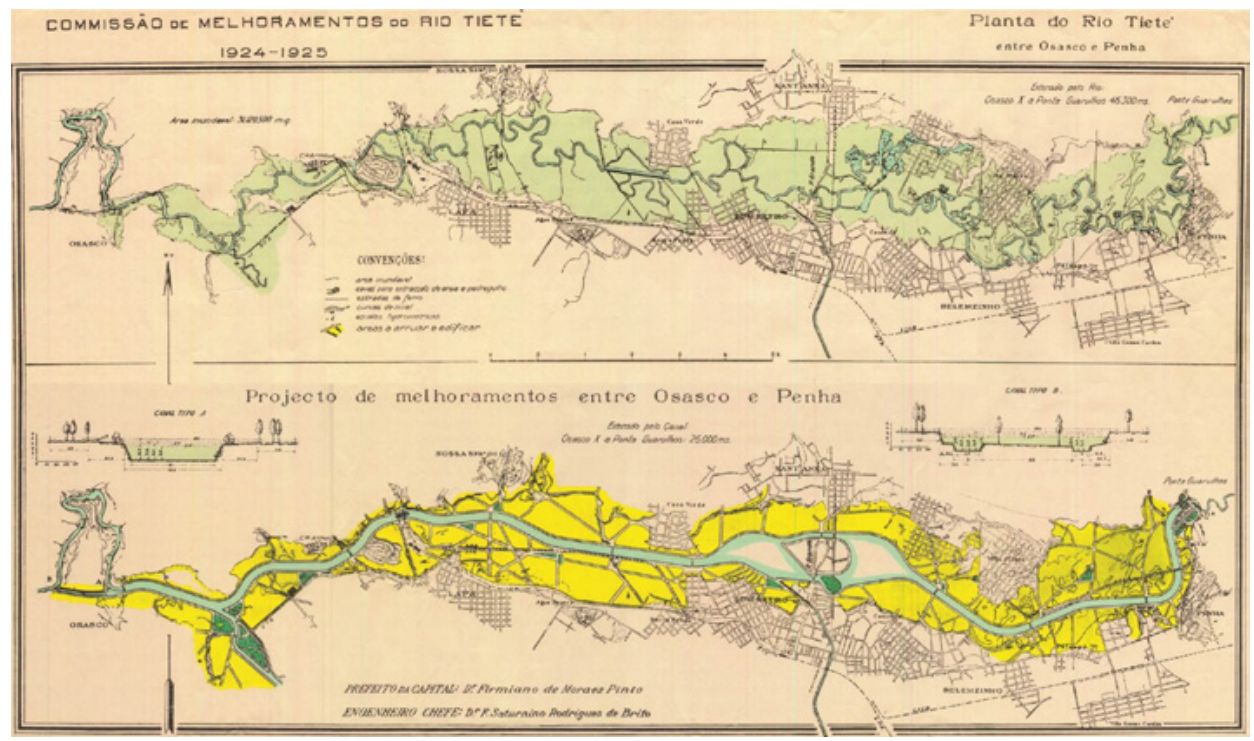

Figura 5 - Projeto de Saturnino de Brito para o Rio Tietê. Fonte: NUNES, M. B., 2004, p. 90

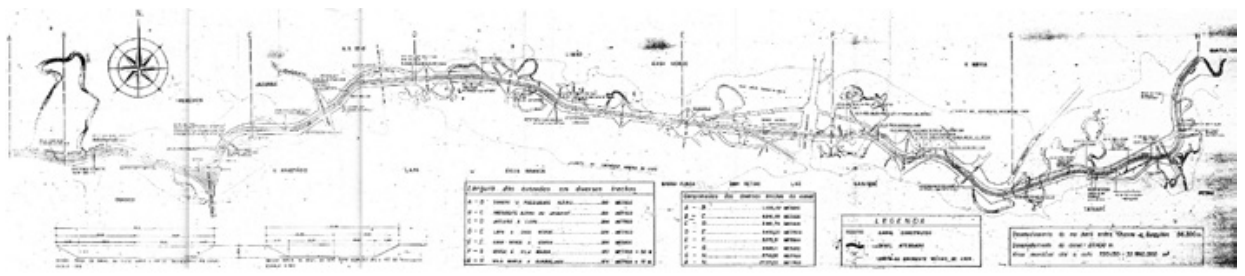

Figura 6 - Projeto para retificação do Rio Tietê. Fonte: NUNES, M. B., 2004, p. 9I

\section{O mapa do zoneamento: mapas e normas, uma relação delicada}

O processo de "construção" de um zoneamento abrangente para toda a cidade de São Paulo se fez em partes, com leis e decretos que trataram inicialmente apenas da região mais central. Segundo Feldman:

Os elementos básicos do zoneamento que se desenvolve a partir de I947 já estavam presentes em três leis aprovadas nos anos I930 e início dos anos I940: o Acto I27 de I93I, a Lei 3.57I de I937 e o Decreto-lei 99 de I94I. Estas leis tratam, respectivamente, da demarcação de uma zona funcional, do controle da verticalização em zonas estritamente residenciais e de parâmetros construtivos no âmbito de uma zona, sendo que as duas primeiras seguem de perto princípios da unidade de vizinhança. Elas atuam como precursoras do processo, que se instaura em I947, de construção do zoneamento na perspectiva de uma lei abrangente ao conjunto da cidade ${ }^{26}$.

26 FELDMAN, S. Planejamento e zoneamento: São Paulo I947-I972. São Paulo: Edusp, 2005, p. I49. 
Embora tenham sido elaborados mapas parciais a partir das leis mencionadas, apenas em I972 a cidade de São Paulo passou a ter um mapa de referência para o uso e ocupação do solo. Cabem neste ponto duas observações: o zoneamento surgiu a partir de um mosaico de regras, e essas regras não configuravam uma postura teórica, com o objetivo de disciplinar previamente o uso do território, mas sim uma regulamentação dos usos já existentes. Nesse caso, a cidade antecedeu o mapa. A segunda observação é que a preocupação com a distinção de usos, gabaritos e coeficientes se limitou a algumas regiões da cidade, e os parâmetros foram definidos sobre um imenso "pano de fundo" classificado no que se denominou zona 2.

Assim, o zoneamento foi definido partindo-se dos casos específicos das áreas central e sudoeste, onde já havia maior adensamento. Na área central, o coeficiente de aproveitamento podia chegar a seis vezes a área do terreno e, na região sudoeste, a quatro. Excetuando-se os núcleos mais adensados, o restante da cidade foi classificado como Z2, zona de uso misto, de baixa densidade, com coeficiente de aproveitamento máximo I e taxa de ocupação de 50\%. Segundo Rolnik:

A Lei de Uso e Ocupação do Solo, de I972, reduziu ainda mais o coeficiente 4, ao permitir que apenas I\% da área da cidade - limitada basicamente ao Centro e à Avenida Paulista, $\mathrm{Z}_{5}$ - pudesse atingir esse potencial. Outros I0\% poderiam chegar a 2 ou 3, e a grande maioria da cidade, incluída na Z2, poderia construir apenas uma vez a área do terreno ${ }^{27}$.

\section{Segundo Fonseca e Oliva,}

A lei se sustentava numa visão exatamente antiurbanidade, na medida em que impedia a densificação e compactação da cidade, assim como a mistura de atividades, o que também impossibilitava a diversidade social. A regressão da urbanidade pode ser debitada na conta do urbanismo dominante, legitimador da setorização e do zoneamento ${ }^{28}$.

O que os autores indicam como antiurbanidade foi reforçado pela lei de zoneamento. Não houve, na produção do zoneamento paulistano, qualquer planejamento de como a cidade deveria ser. A segregação espacial já estava presente, e o zoneamento tratou apenas de cristalizá-la.

Feldman nos mostra que o zoneamento da cidade de São Paulo foi sendo montado a partir de I947, como um mosaico de leis, para somente em I972 tornar-se uma lei que abrangia todo o território municipal. Além disso, ela destaca que o zoneamento é a expressão das ações concretas, sem qualquer elaboração a priori, e sim um "ir fazendo" para adaptar a situação fática ou os interesses de grupos a uma norma legitimadora:

27 ROLNIK, R. A cidade e a lei: legislação, política urbana e territórios na cidade de São Paulo. São Paulo: Studio

Nobel, I997, p. 200.

28 FONSECA, Fernanda Padovesi; OLIVA, Jaime, op. cit., p. 3I. 
O zoneamento se constrói “ao vivo", por partes, diretamente articulado à dinâmica de alguns setores da cidade, confirmando a hipótese discutida por Mancuso (I978: I7) de que o zoneamento não é um instrumento “disciplinar”, não resulta de uma postura teórica, mas é resultado de uma série de ações desenvolvidas pelas municipalidades e experimentadas diretamente na cidade, antes mesmo de serem codificadas. Nesse sentido, segundo o autor, tanto as características estruturais do zoneamento, como os parâmetros que opera e os setores da cidade nos quais intervém, nascem com a necessidade de responder aos objetivos de caráter econômico, político e social colocados pelos conflitos gerados com o crescimento acelerado das cidades ${ }^{29}$.

\section{MAPEANDO PAISAgENS: A CARTOGRAFIA NA GEOGRAFIA CULTURAL HUMANISTA}

A paisagem na geografia cultural humanista assume diferentes formas de interpretação: ela pode ser a interpretação do que se vê, segundo as experiências pessoais do observador, mas também um espaço organizado, onde se pode identificar os processos sociais que levaram à sua formação.

$\mathrm{O}$ aspecto subjetivo da paisagem, o da interpretação de quem a vê, passa também pela forma como se vê: a perspectiva a partir da qual o observador se posiciona para observar a paisagem é determinante para a sua compreensão e interpretação.

Segundo Besse:

[...] não consideramos sempre as paisagens sob o mesmo ângulo, nem a partir do mesmo ponto de vista. Podemos vê-las do alto, como um pássaro, ou a partir do topo de uma montanha, numa espécie de afastamento e de obliquidade sintética, ou as olhamos a partir delas mesmas, ou seja, de seu interior, e vemos as coisas, por assim dizer, por seu contorno, pelos lados, e nunca realmente de maneira completa. Essas duas maneiras de ver, a visão vertical, assim como a visão lateral, a síntese e o movimento, fazem parte, ambas, da nossa relação com a paisagem. E geralmente nossa relação visual com a paisagem divide-se em uma ampla gama de olhares, ângulos e pontos de vista que não são sempre compatíveis, mesmo que coexistam ${ }^{30}$.

Essas diversas maneiras de ver a paisagem implicam também diferentes formas de representá-la: as imagens produzidas para representação das paisagens na forma de pinturas, fotografias ou mapas consideram uma dessas perspectivas ou, por vezes, mais de uma.

Em termos de representação, Cosgrove ${ }^{3 \mathrm{I}}$ ressalta a importância da perspectiva voo de pássaro na produção das imagens representativas das paisagens. Esse é um recurso que foi utilizado nas primeiras representações pictóricas da paisagem. Ele

29 FELDMAN, Sarah, op. cit., p. I64.

30 BESSE Jean-Marc. Entre a geografia e a ética: a paisagem e a questão do bem-estar. Trad. Eliane Kuvasney e

Mônica Balestrin Nunes. GEOUSP - espaço e tempo, São Paulo, v. I8, n. 2, p. 24I-252, 20I4, p. 24 I.

3I COSGROVE, Denis Edmund, I998, op. cit. 
permite a visão de cima, não propriamente zenital, mas a partir da perspectiva de quem se situa num plano mais elevado em relação ao que se observa.

Como se observa na história da cartografia, nem sempre os mapas são produzidos para representação zenital da paisagem. No Renascimento, com o surgimento da perspectiva, a visão "voo de pássaro" passa a ser adotada para a representação das cidades. O recurso da perspectiva na produção iconográfica pode ser interpretado como uma busca de representação que permita a "visão de cima”, uma elevação em relação ao plano horizontal, e que denote poder sobre o que se vê.

Thürlemann, em estudo sobre a representação das paisagens na perspectiva voo de pássaro, mostra que esse tipo de representação era elaborado inicialmente a partir da projeção ortogonal para, depois, ter seu plano "inclinado”:

Antes de ter tido a possibilidade de olhar a superfície da terra a partir de balões e de aviões, o homem desenhou mapas e plantas de cidades a voo de pássaro, como ainda o chamam hoje - e isto independentemente da possibilidade de uma vista real inclinada a partir de montanhas ou de torres. [...]

O mapa a voo de pássaro pressupõe uma tomada prévia ortogonal, isto é, perpendicular, da superfície representada. Subsequentemente, esta tomada é submetida a uma perspectiva oblíqua ${ }^{32}$.

Cosgrove aponta que a perspectiva voo de pássaro, além de denotar a relação de poder em relação ao objeto, também permite certa generalização da informação, transformando e dando outro sentido à paisagem. Assim:

A perspectiva do olho do pássaro é perfeita para demonstrar a elegância e a prosperidade das cidades recém-criadas e muitas vezes mal construídas. Enfatizando sua grade de ruas com a agitação de carruagens e carroças, os mapas muitas vezes mostraram lugares caóticos e violentos como comunidades civicamente bem -ordenadas 33 .

A essas formas de representação correspondem mapas produzidos em momentos históricos diversos, não sendo uma produção exclusiva do Renascimento, mas perdurando até os dias de hoje.

A perspectiva voo de pássaro talvez seja a forma mais eficiente de representar paisagens, mas não é a única. As representações em plano ortogonal, da cartografia euclidiana, podem também representá-las. A leitura do plano ortogonal permite identificar elementos da morfologia da paisagem que a distinguem de outras paisagens: o traçado viário, a existência de espaços livres, a arborização, a hidrografia

32 THÜRLEMANN, Felix. Olhar como os pássaros. Sobre a estrutura de enunciação de um tipo de mapa cartográfico. Galáxia - Revista do Programa de Pós-graduação em Comunicação e Semiótica, São Paulo, n. 22, p. II8-I32, dez. 2OII, p. I2I-I22

COSGROVE, Denis Edmund, I998, op. cit., p. I.954. 
são elementos que podem ser identificados primeiramente no plano para depois serem vistos a partir da perspectiva do observador.

A cada projeção ortogonal corresponde uma elevação, de modo que diferentes planos ortogonais produzem diferentes elevações e, por consequência, diferentes paisagens.

Jean-Marc Besse, no prefácio da tradução francesa de Discovering the vernacular landscape, de J. B. Jackson ${ }^{34}$, cita outra obra do mesmo autor, The necessity of ruins:

O objeto principal que deve preocupar aquele que estuda as paisagens (notemos este plural), é por consequência, escreve Jackson em The necessity of ruins, a maneira pela qual o espaço é organizado pela comunidade, isto é, como ela traça a fronteira, mas também reparte as parcelas entre as famílias, constrói estradas e um lugar para reuniões públicas, e reserva terra para uso comum ${ }^{35}$.

Essas formas podem ser vistas em projeção, por meio de mapas feitos a partir da visão ortogonal, e, ainda assim, revelam paisagens. É nesse sentido que os mapas, sejam representações em perspectiva ou em projeção, permitem a leitura das paisagens. Mas não é só pelos elementos físicos, como coloca Jackson, que a paisagem pode ser lida por meio dos mapas: a compreensão do contexto histórico e da sociedade permite a leitura da paisagem cultural, das relações entre a materialidade objetiva e os significados a ela atribuídos.

Nesse aspecto, retornamos ao início do artigo: os mapas, para além de representar a realidade existente ou a possibilidade de uma nova realidade, denotam também as relações sociais, econômicas e culturais do contexto em que foram produzidos.

Cabe ao profissional dos estudos urbanos, portanto, ao se deparar com esse tipo de representação, buscar compreender o contexto e extrair dessa análise subsídios para seu trabalho.

No caso específico dos geógrafos, Seemann, ao elaborar uma revisão bibliográfica sobre a cartografia na geografia cultural humanista, sintetiza o seu papel em relação ao ofício:

As habilidades se dividem entre o geógrafo que sabe produzir e ler mapas e o geógrafo que mapeia e interpreta as complexas relações entre espaço e cultura. O caso ideal é quando o geógrafo consegue conectar produto e processo, política e poética, analogia e metáfora ${ }^{36}$.

34 JACKSON, John. Brinckerhoff. A la découverte du paysage vernaculaire. Arles: Actes Sud, 2003, 278 p.

35 BESSE, J. M.; TIBERGHIEN, G. A. Préface. In: JACKSON, John Brinckerhoff. A la découverte du paysage vernaculaire. Arles: Actes Sud, 2003.

36 SEEMANN, Jörn. Cartografia e cultura: abordagens para a geografia cultural. In: ROSENDAHL, Zeny; CORREA, Roberto Lobato (Org.). Temas e caminhos da geografia cultural. Rio de Janeiro: Editora da UERJ, v. I, p. II5-I56, 20IO, p. I2. 
MÔNICA BALESTRIN NUNES é geógrafa, mestre em Arquitetura e Urbanismo pela Faculdade de Arquitetura e Urbanismo (FAU/USP), doutora em Geografia Humana pela Faculdade de Filosofia, Letras e Ciências Humanas (FFLCH/USP) e analista de infraestrutura do Ministério das Cidades.

E-mail: monibalestrin@gmail.com

\section{REFERÊNCIAS BIBLIOGRÁFICAS}

ANTONUCCI, Denise. Sagmacs: o estudo que fez escola. In: SOMEKH, N.; CAMPOS, C. M. et al. A cidade que não pode parar. São Paulo: Mackpesquisa, 2002, p. 95-I08.

ARCHELA, Rosely Sampaio. História da cartografia no Brasil: instituições, formação profissional e técnicas cartográficas. Revista Brasileira de Cartografia, n. 59, p. II-37, dez. 2007.

BESSE Jean-Marc. Entre a geografia e a ética: a paisagem e a questão do bem-estar. Trad. Eliane Kuvasney e Mônica Balestrin Nunes. GEOUSP - espaço e tempo. São Paulo, v. I8, n. 2, p. 24I-252, 2014.

BESSE, J. M.; TIBERGHIEN, G. A. Préface. In: JACKSON, John Brinckerhoff. A la découverte du paysage vernaculaire. Arles: Actes Sud, 2003.

BRITO, Francisco Saturnino Rodrigues de. Obras completas. V. XIX. Defesa contra inundações. Rio de Janeiro: Imprensa Nacional, I944.

CESTARO, Lucas. Urbanismo e humanismo: a Sagmacs e o estudo da estrutura urbana da aglomeração paulistana. Dissertação (Mestrado em Teoria e História da Arquitetura e do Urbanismo). Programa de Pós-graduação em Arquitetura e Urbanismo. Escola de Engenharia de São Carlos, Universidade de São Paulo, 2009.

COSGROVE, Denis. Edmund. Social formation and symbolic landscape. Wisconsin: The University of Wisconsin Press, I998, 293 p.

. Carto-city. In: ABRAMS, J.; HALL, P. (Org.). Else/where: mapping - new cartographies of networks and territories. Minneapolis: University of Minnesota Design Institute, 2006.

FELDMAN, Sarah. Planejamento e zoneamento: São Paulo I947-I972. São Paulo: Edusp, 2005.

FONSECA, Fernanda Padovesi. A inflexibilidade do espaço cartográfico, uma questão para a geografia: análise das discussões sobre o papel da cartografia. Tese (Doutorado em Geografia Humana). Departamento de Geografia da Faculdade de Filosofia, Letras e Ciências Humanas, Universidade de São Paulo, São Paulo, 2004.

FONSECA, Fernanda Padovesi; OLIVA, Jaime. Reflexões sobre o urbano, a cartografia e a iconografia: o caso da metrópole de São Paulo. Revista Geografia e Pesquisa, Ourinhos, v. 5, n. 2, p. II-38, 20I3, p. 29-30.

HARLEY, B. Mapas, saber e poder. Tradução Mônica Balestrin Nunes. Confins - Revista Franco-Brasileira de Geografia, n. 5, 2009. Disponível em: 〈http://confins.revues.org/5724〉. Acesso em: nov. 2016.

JACKSON, John Brinckerhoff. De la nécessité des ruines et autres sujets. Paris: Éditions Du Linteau, 2005, I95 p. . A la découverte du paysage vernaculaire. Arles: Actes Sud, 2003, 278 p.

LIMA, Erly Caldas de. O levantamento pioneiro da Sara Brasil: histórico, tecnologia empregada e avalia- 
ção dos produtos. Dissertação (Mestrado em Engenharia). Escola Politécnica, Universidade de São Paulo, 2013.

LUSSAULT, Michel. L'homme spatial: la construction sociale de l'espace humain. Paris: Éditions du Seuil, 2007. (Coll. La couleur des idées).

NUNES, Mônica Balestrin. A configuração espacial da várzea do Rio Tietê: a região da Água Branca e as áreas públicas municipais. Dissertação (Mestrado em Estruturas Ambientais Urbanas). Faculdade de Arquitetura e Urbanismo, Universidade de São Paulo, São Paulo, 2004

ROLNIK, Raquel. A cidade e a lei: legislação, política urbana e territórios na cidade de São Paulo. São Paulo: Studio Nobel, I997.

SANTOS. Boaventura Sousa. Uma cartografia simbólica das representações sociais: prolegómenos a uma concepção pós-moderna do direito. Revista Crítica de Ciências Sociais, n. 24, março de I988, p. I39-I72. Disponível em: <http://www.boaventuradesousasantos.pt/pages/pt/artigos-em-revistas-cientificas. php>. Acesso em:Ir jun. 2014

SEEMANN, Jörn. Cartografia e cultura: abordagens para a geografia cultural. In: ROSENDAHL, Zeny; CORREA, Roberto Lobato (Org.). Temas e caminhos da geografia cultural. Rio de Janeiro: Editora da UERJ, 20IO, v. I, p. II5-I56.

THÜRLEMANN, Felix. Olhar como os pássaros. Sobre a estrutura de enunciação de um tipo de mapa cartográfico. Galáxia - Revista do Programa de Pós-graduação em Comunicação e Semiótica, São Paulo, n. 22, p. II8-I32, dez. 20II.

VERGARA, Moema Rezende; CAPILÉ, Bruno. A Comissão da Carta Geral do Império (I862-I878) e sua participação no contexto da cartografia brasileira no Império. In: SIMPÓSIO BRASILEIRO DE CARTOGRAFIA HISTÓRICA, I. Anais..., Paraty, RJ, Io a I3 de maio de 20II. Disponível em: <https://www. ufmg.br/rededemuseus/crch/simposio/VERGARA_MOEMA_R_E_CAPILE_BRUNO.pdf $>$. Acesso em: 25 ago. 20I4. 